\title{
BOND STRENGTH OF BAR USING GROUTING FOR PRECAST CONCRETE CONNECTION
}

\author{
Anis Rosyidah ${ }^{1}$, I Ketut Sucita ${ }^{2}$, Praganif Sukarno ${ }^{3}$, S.R. Permita Sari ${ }^{4}$, Chintya Sari ${ }^{5}$ \\ 1, 2, 3 Civil Engineering Department, Politeknik Negeri Jakarta, Depok, 16425, Indonesia \\ ${ }^{4,5}$ Civil Engineering Department, Politeknik Negeri Jakarta, Depok, 16425, Indonesia \\ e-mail: anis.rosyidah@sipil.pnj.ac.id ${ }^{1}$, cita.sand@gmail.com², ganif@sipil.pnj.ac.id
}

\begin{abstract}
In precast concrete, a connection is needed to unite the components so that they become a whole unified structure. This study aims to determine the reinforcement strength and length of reinforcement in precast concrete connections. To paste reinforcement into precast concrete, giving additional material in the form of grouting which is called sika grout 215 and functions as an adhesive is necessary. Pullout testing is carried out in the laboratory, and its simulation by modeling uses the finite element method based software. This research is divided into 2 phases. The first phase is making specimen to examine the bond strength between the concrete and reinforcement that has been given sika grout 215. So monolithic specimen is made as a comparison. The result of the bond strength of the monolithic test specimen is $6.24 \mathrm{MPa}$, and the sika grout 215 category is 6.52 MPa. From the experimental results in the laboratory with modeling, it is obtained the bond strength ratio of 0.94. The length of development (ld) based on the results of the testing phase I of $200 \mathrm{~mm}$. The second phase is examining the damage pattern due to the stress that occurred. Specimens are made into 4 categories, namely modeling developments with the length of 120 $\mathrm{mm}(<40 \% \mathrm{ld})$, with the length of $160 \mathrm{~mm}(<20 \% \mathrm{ld})$, with length of $200 \mathrm{~mm}(=l d)$, and with the length of $260 \mathrm{~mm}$ (>30\% ld) both for monoliths and sika grout 215. The damage pattern, which is in the form of yielding and breaking reinforcement as the result of the pullout experiment in the laboratory shows not much different from the result of simulation using the software.
\end{abstract}

Keywords: Bond strength; Damage pattern; Development length; Precast reinforced concrete connections; Pullout test

\section{INTRODUCTION}

The precast concrete structure as fabricated components are connected one and another in the work location in order to make the precast component form a complete structure. The precast concrete components assembling requires specific connection techniques. The most common connection method in precast construction is by implanting more extended reinforced steel that forms a pass through the hardened precast concrete. Then an adhesive substance is added to unite the reinforcement and the concrete (Hosseini, 2015, and Abd. Rahman, 2015). The connection is considered stable if there is no slip between the reinforcing steel and the concrete so that the exact length of reinforcement is needed, as well as the durable adhesive substance, to hold the tensile force on the connection (Rosyidah, 2011, and Lu, 2012)

In order to get the best bonding strength between the hardened concrete and reinforcement requires a robust adhesive substance. Expectedly, the adhesive material in the form of grouting can increase the bond strength between concrete and reinforcement with its advantages in its fast initial strength, resistant to shrinkage compensated, high resistant strength, non-corrosion and nontoxic (Lu, 2017, and Raynor, 2002). 
The bond strength is the maximum bonding value between the reinforcement and its surrounding concrete (Paulay and Priestley, 1992). This adhesive plays an essential role in designing the concrete structure. The factors that influence this stickiness are quite numerous and complex. The factors that determine this bond strength, namely adhesion, friction, and interlocking force (Xing, et al., 2015). In thread reinforcement, besides bond and friction, there is an interlocking force that occurs in reinforcement and concrete. This force causes more exceptional sticking ability of threaded reinforcement compared to plain reinforcement (Xing, et al, 2015, Feldman and Bartlett, 2007, and Hong and Park, 2012).

The adhesive stress value of pullout testing can be calculated as adhesive stress along with the embed of reinforcement in concrete (Harajli, et al, 2004, Zhao, et al, 2012, and $\mathrm{Wu}$ and Zhao, 2012). The equation of the bonding stress surface average along the reinforcement inserted in the concrete is presented in eq. (1).

$$
\tau=\frac{P}{\pi \cdot D \cdot L}
$$

$\mathrm{P}=$ pullout, $\mathrm{D}=$ reinforcement diameter, $\mathrm{L}=$ length of reinforcement adhered to the concrete.

In order to get the best result, both the experimental testing and modeling using finite element software. Then, the result of the experimental test including bond strength, length of development and pattern of specimen collapse is compared to the one through modelling.

\section{METHODS}

This research is divided into 2 phases. Phase 1 is to examine the bond strength between the concrete and reinforcement given the added grouting material. Phase 2 is to examine the length of development (ld) of reinforcement embedded in the concrete along with the damage pattern that occurs. The specimens used to obtain the bond strength of reinforcement in concrete by grouting use a cubed form standard with a size of $200 \times 200$ $\times 200 \mathrm{~mm}$. The concrete used in ready-mix concrete with a quality of $25 \mathrm{MPa}$. Concrete with its reinforcement, sika grout 215 grouting material is used. The hole in the concrete is formed from a 1-inch diameter pipe at the casting process. When the concrete hardens, the hole is then filled with reinforcement and grouting with a thickness of 11,025 $\mathrm{mm}$ (Figure 1). Reinforcement used is deformed steel with a diameter of 10 mm with BJTS 50 steel quality. The specimens are made as many three pieces. As a comparison, concrete specimens are also made with reinforcement, which is cast monolithically. The same specimens are then modeled in finite element software so that the results of experiments and modeling can be compared.

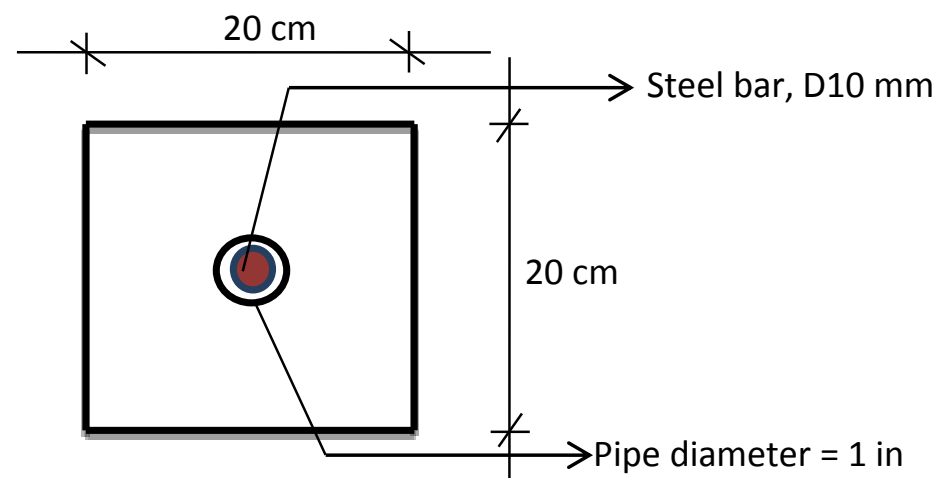

Figure 1. Top view of the specimen 
RESULTS AND DISCUSSION

The Bond Strength
The calculation results of the bond strength of the monolith (M) model, and the one using grouting (SG) are obtained, as shown in Figure 2.

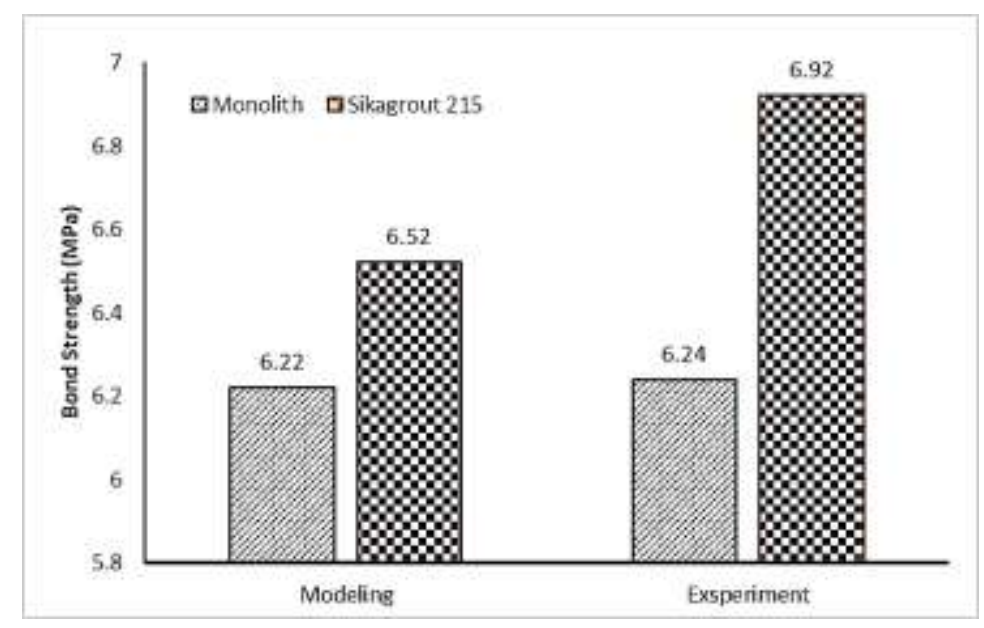

Figure 2. The bond strength of specimens from laboratory testing and modeling

The calculation results of adhesive stress using monolithic specimens (M) and specimens using Sikagrout 215 show that the response of bond strength values both the results of modeling and testing in the laboratory are significant. It can be seen from the ratio of the difference in bond values of monolithic (M) modeling and experiment with the ratio of 0.997 and the test object using Sikagrout 215 modeling and experiment which has a ratio of 0.942 . The results of the comparison between non-linear modeling analysis with the experimental results obtained a ratio between 1.03 to 1.67 with fc $20.668 \mathrm{MPa}$. Bond strength obtained from specimens cast by monolith as well as those using sika grout 215 , both show similar results. The bond strength value of the specimen in solid modeling is $6.22 \mathrm{MPa}$, and the value of the specimen with Sikagrout 215 grouting is $6.52 \mathrm{MPa}$. The result shows that the bond strength with Sikagrout 215 grouting has a higher bond than the one at the monolithic specimen.

\section{Result of Development Length of Model Specimen}

The development length value of the monolithic specimen model is $194.25 \mathrm{~mm}$, and sika grout of 215 is $193.43 \mathrm{~mm}$. The results of the development length of monolith and sika grout specimens are relatively equal. The result of the specimen using sika grout of 215 only needs a slightly shorter development length than the monolithic specimen. For more details, the development length difference between monolithic specimens and Sikagrout grouting of 215 can be seen in the diagram of the development length requirements in Table 1. 
Table 1. The Comparison of the Development length Results between Modeling and Testing

\begin{tabular}{lrr}
\hline & \multicolumn{2}{c}{ Development Length (mm) } \\
& Monolith & Sikagrout 215 \\
\hline Modeling & 194.66 & 193.43 \\
Exsperiment & 194.25 & 182.22 \\
\hline Ratio & 1.002 & 1.062 \\
\hline
\end{tabular}

The comparison ratio between the bond stress and the development length obtained from experiment and modeling was almost close to one. The development length of the monolith specimen is $1,94.66 \mathrm{~mm}$, and the experiment is $194.25 \mathrm{~mm}$. For modeling, The development length specimen with Sika grout of 215 groutings was $1.93 \mathrm{~mm}$, and the experiment was 182.22 $\mathrm{MPa}$. The results show that the development length with the addition of Sikagrout of 215 was relatively equal to the development length produced from the specimen cast monolithically.

\section{The Specimen Collapse Pattern}

After obtaining the comparison between the bond strength and development length, then the pattern of damage should be found. For this reason, it is made the specimen model variation based on the length of development obtained in phase 1, which is $200 \mathrm{~mm}$. It is also made monolithic specimen model of the same variation for comparison. There are 4 types of the model i.e. development length of $120 \mathrm{~mm}(<40 \%$ ld) model, development length of $160 \mathrm{~mm}(<20 \%$ ld), development length of $200 \mathrm{~mm}(=\mathrm{ld})$, and development length of $260 \mathrm{~mm}$ (> 30\% ld) both for monoliths and sika grout of 215 .

The pattern of Specimen Damage with Development Length ( $<40 \%$ ld) $120 \mathrm{~mm}$.

The stress value at the model is shown to identify the damage occurs.

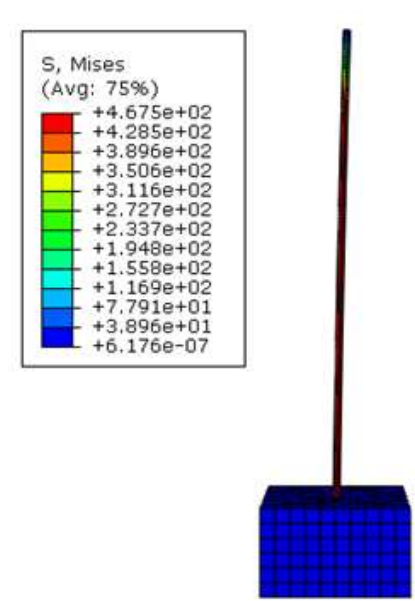

(a)

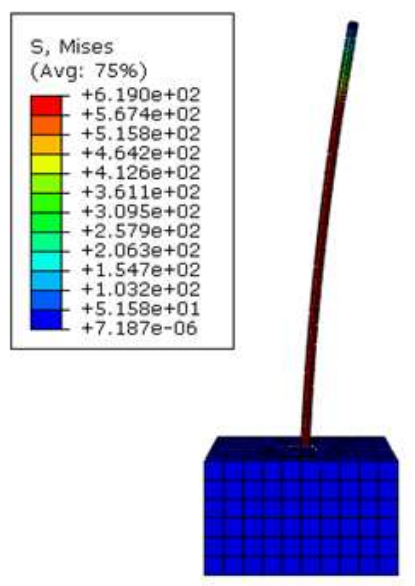

(b)

Figure 3. Stress on Model of (a) Monolith ld 120mm (Ma); (b) Sikagrout 120mm (SGa)

The specimen of Ma has the maximum stress of $467.5 \mathrm{MPa}$ in step 37 with a load of 32540
$\mathrm{N}$ (Figure 3). The maximum stress of $\mathrm{SGa}$ is $619 \mathrm{MPa}$ in step 22 with the load of $44970 \mathrm{~N}$. 
The SGa specimen is yielding at the load of 44970 because the occurred stress value has been over the limit of yielding stress 505,164 $\mathrm{MPa}$.

From the value of the bond strength obtained, the concrete does not undergo slip because both the bond strength of the monolith or sika grout specimen are higher than the value of the concrete stress or the occurred grouting. The occurred damage pattern is different from the pattern of damage to the research. It slips on the Ma monolithic specimen and the SGa broken specimen, as seen in Figure 4.
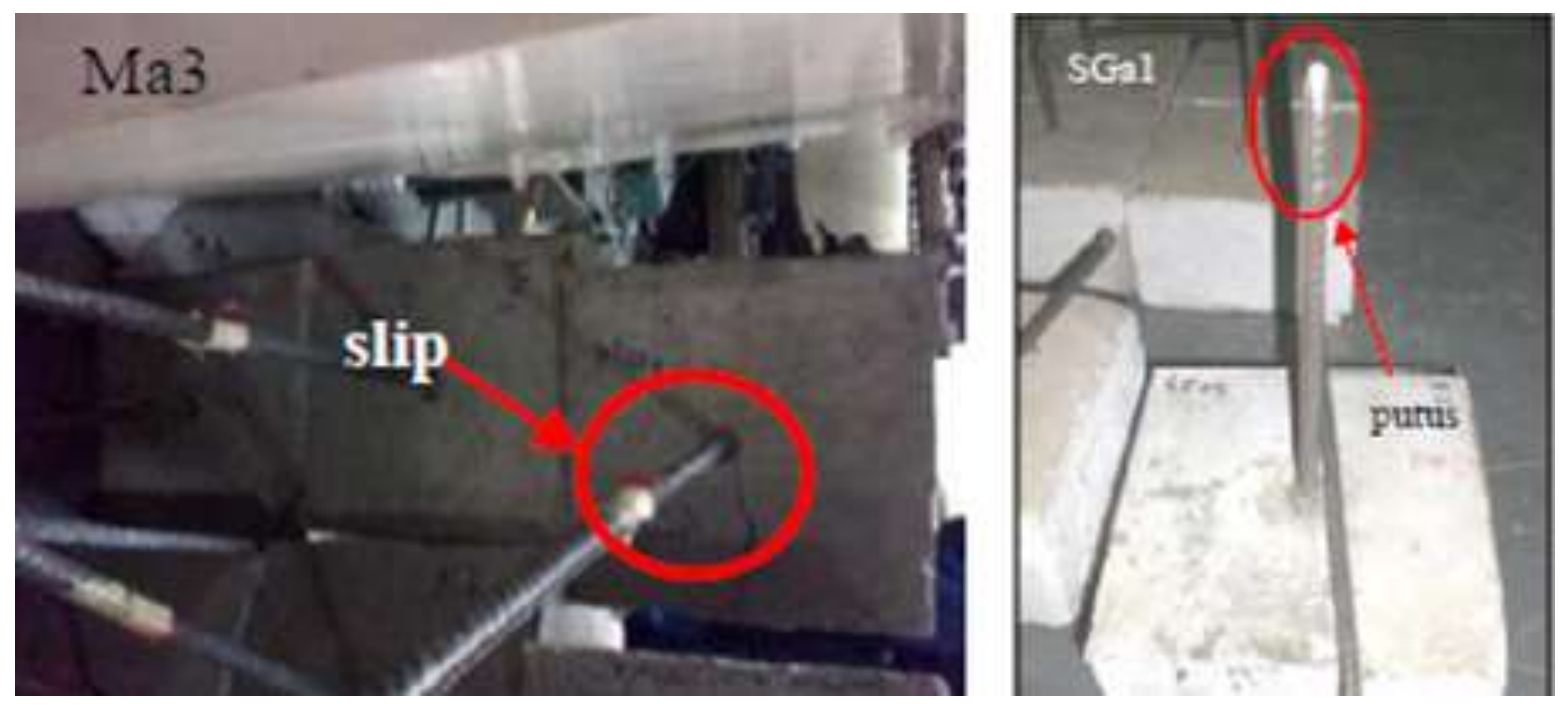

Figure 4. Damage to Specimen as the result of Ma and Sga Experiments

\section{Specimen Damage Pattern with Development Length of 160 mm $(<20 \%$ ld $)$}

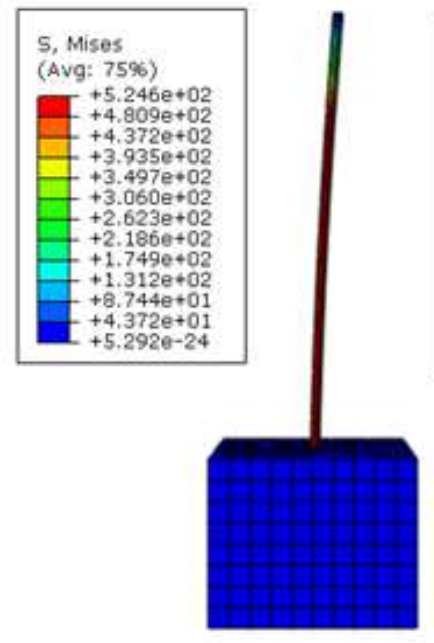

(\$)
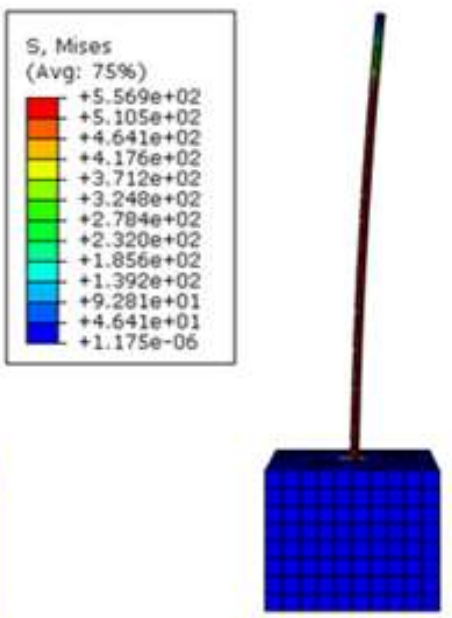

(b)

Figure 5. Stress on (a) Monoliths ld 120mm (Ma) and Sikagrout ld 120mm (Sga) Models

The results of the stress identification at $\mathrm{Mb}$ specimen has the maximum stress of 524,623 $\mathrm{MPa}$ at step 31 with the load of $39800 \mathrm{~N}$ (Figure 5). The specimen of SGb 556,886
MPa at step 21 with the load of $40220 \mathrm{~N}$. Mb undergoes yielding at $37030 \mathrm{~N}$, and SGb undergoes yielding at the load of $37870 \mathrm{~N}$, because of the value of the stress that occurs 
is over than the yielding stress limit. The specimen of $\mathrm{Mb}$ is increasing when the concrete fault due to the load of $8.10 \mathrm{~mm}$ at a maximum load of $39800 \mathrm{~N}$. The modeling of $\mathrm{SGb}$ specimens undergoes the concrete fault of $7.5 \mathrm{~mm}$ during the same conditions with the load of around $39800 \mathrm{~N}$. From the length comparison, the reinforcement of the SGB test using sika grout has smaller change than the $\mathrm{Mb}$ of the specimen made by the monolith.
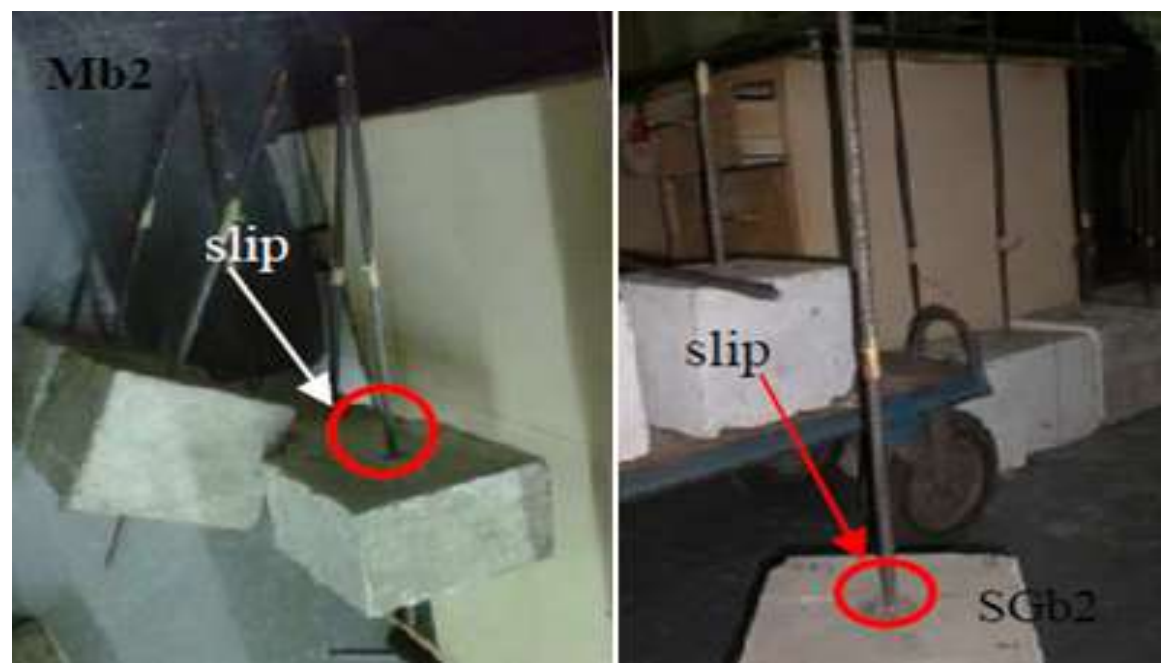

Figure 6. Damage to $160 \mathrm{~mm}(\mathrm{Mb})$ and Sikagrout ld 160mm (Sgb) Monolithic specimens

Results and Analysis of Specimen Damage Patterns with Development Length of $200 \mathrm{~mm}$ (= ld)
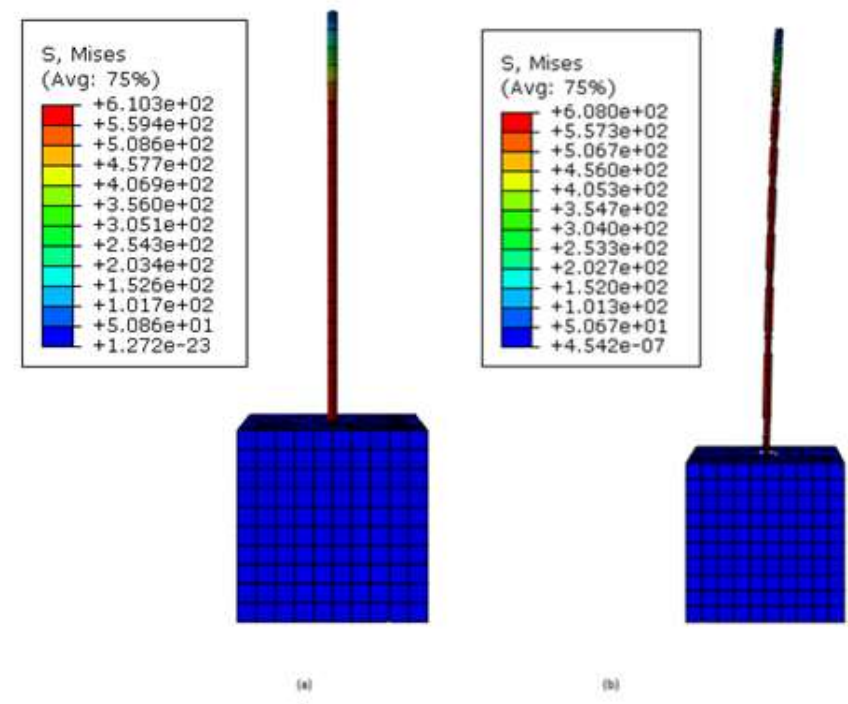

Figure 7. Stress on (a) Monoliths ld 200mm (Mc); (b) Sikagrout ld 200mm (SGC) Models 
The Figure 7, Mc shows the maximum stress of $610.28 \mathrm{MPa}$ in step 28 with the load of $44150 \mathrm{~N}$ and the Sgc maximum stress of 608 MPa in step 25 with the load of 43930 N. Mc undergoes yielding with the load of $37900 \mathrm{~N}$ and $\mathrm{Sgc}$ has at its load of $34680 \mathrm{~N}$. The stress on the load of $44210 \mathrm{~N}-44380 \mathrm{~N}$ in software. It is caused the broken reinforced steel, and its stress has been over the steel fracture stress limit, which is $632,042 \mathrm{~N}$.
The concrete does not undergo slip since the bond strength of both the $\mathrm{Ma}$ and $\mathrm{SGa}$ specimens is bigger than the value of the concrete stress or the occurred grouting. The pattern of damage for $200 \mathrm{~mm}$ variation specimens for Mc test specimens is yielding on reinforcement while in SGc specimen undergoes breaking on reinforcement. This pattern of damage is almost identical to the pattern of damage in the research, as shown in Figure 8. However, there is still yielding on Mc specimen.
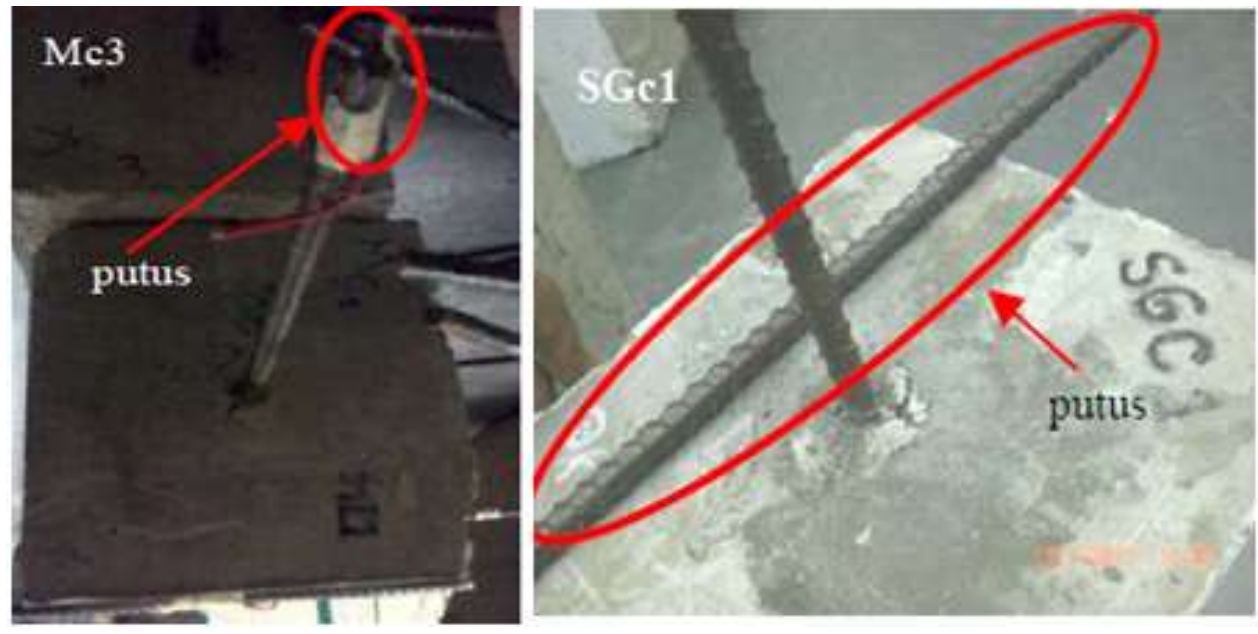

Figure 8. Damage to Monolithic Specimen of ld 200mm (Mc) and Sikagrout of ld 200mm (SGC)

Results and Analysis of Specimen Damage Patterns with the Development Length (> 30\% ld) $260 \mathrm{~mm}$
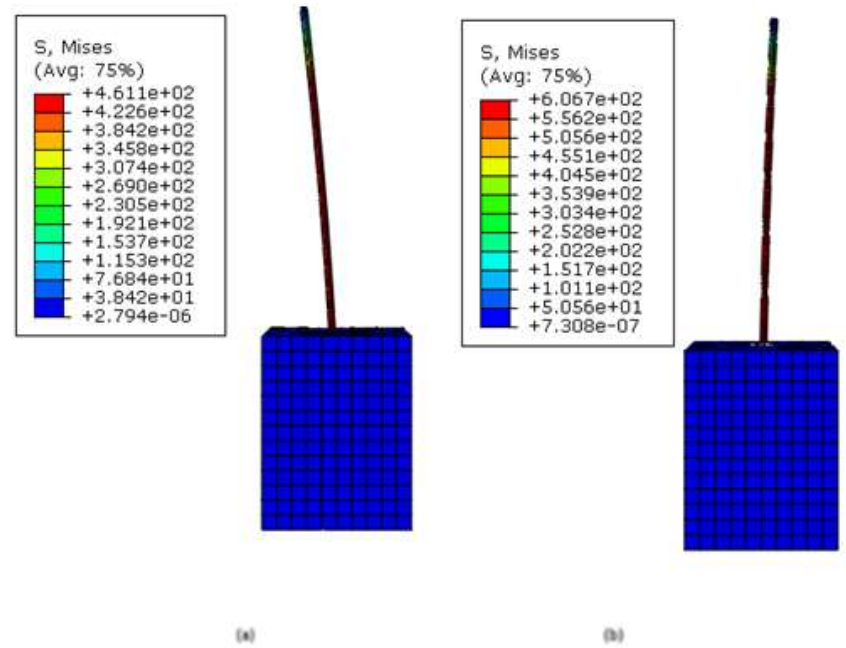

Figure 9. Stress on (a) Monolith ld 260mm (Md); (b) Sikagrout ld 260mm (Sgd) Models 
The maximum stress of $\mathrm{Md}$ reaches on 461.07 MPa. It is on step 14 with the load of 29140 N. After passing through the load, the stress on Md cannot be read because of yielding and breaking, and the SGd specimen reaches the maximum stress of $606.738 \mathrm{MPa}$ in step 21 with the load of $43790 \mathrm{~N}$. The SGd undergoes yielding on the load of $34450 \mathrm{~N}$ which is caused by the over-limit value of stress.

Form the value of the bond strength obtained; the concrete does not undergo slip because the bond strength of both Ma and SGa specimens is more significant than the value of the concrete stress or the occurred grouting. The damage pattern occurred to 260 mm specimen type of Md undergoes breaking on the reinforcement while the specimen of Sgd undergoes yielding on the reinforcement, The damage pattern occurs slightly different from the damage pattern in the research which undergoes slip on the monolith Md and Sgd specimen undergoes fracture on the reinforcement, as shown in Figure 10.

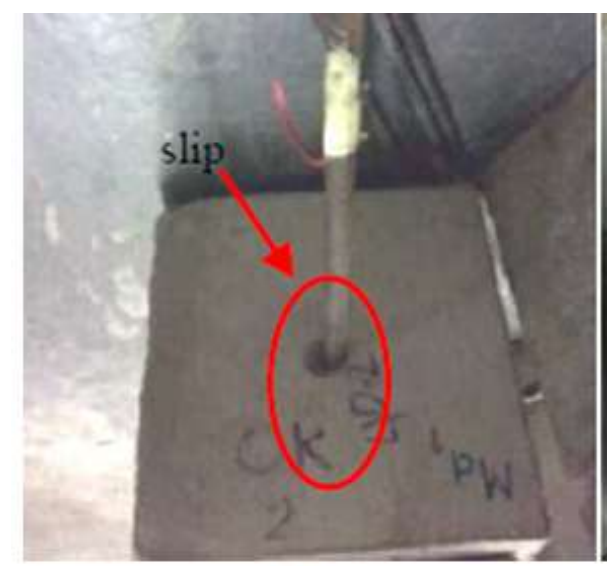

(a)

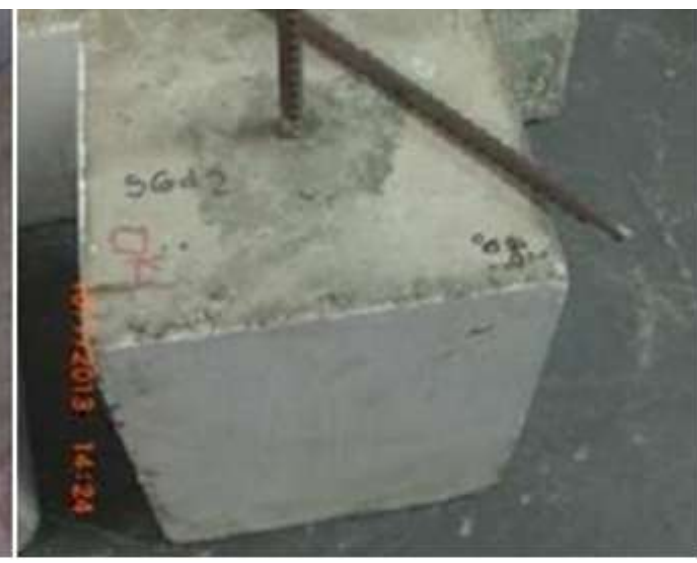

(b)

Figure 10. Damages to Monolith ld 260mm (Md) and Sikagrout ld 200mm (Sgd) specimens

\section{CONCLUSION}

The conclusion can be drawn from the specimen experiment and modeling as follows: The bond strength of the monolith specimen is $6.24 \mathrm{MPa}$, and the bond strength of specimen using sika grout 215 is 6.52 $\mathrm{MPa}$. The ratio of the results in the model experiment is 0.9 .

The bond stress of the specimen with additional Sikagrout of 215 is as good as the bond stress produced by reinforced steel, which is directly cast together with the concrete or monolith. It indicated by the equal value of the bond stress and the development length needed for each development length variation. The damage pattern occurred is the yielding of reinforcement due to the value of stress occurred in the modeling over the limit of the breaking value of reinforced steel stress.

The occurred bond stress is varied when the reinforcing steel reaches yielding at an equal diameter which has been caused by the area of contact reinforced steel concrete that is also varied because of the different length of the development. The smallest bond stress is 5.773 $\mathrm{MPa}$, and the biggest one is $9,803 \mathrm{MPa}$, while the force needed to achieve reinforcement steel up to yielding is relatively equal, around $34450 \mathrm{~N}-37870 \mathrm{~N}$ for the equal quality and diameter of reinforced steel. 


\section{ACKNOWLEDGMENT}

Special acknowledgment to the Ministry of Research, Technology and Higher Education, the Research and Community Center Politeknik Negeri Jakarta for providing research funding grants, and also the Research and Housing Development Center of Bandung that has provided the place of experiment for this research.

\section{REFERENCES}

Abd Rahman, A.B., M. Mahdinezhad, I. S. Ibrahim, and R. N. Mohamed. (2015) "Bond stress in grouted spiral connectors," J. Teknol., vol. 77, no. 16, pp. 49-57.

Feldman, L.R., and F. M. Bartlett. (2007). "Bond stresses along plain steel reinforcing bars in pullout specimens," ACI Struct. J., vol. 104, no. 6, pp. 685692.

Harajli, M.H, B. S. Hamad, and A. A. Rteil. (2004) "Effect of Confinement on Bond Strength between Steel Bars and Concrete," ACI Struct. J., vol. 101, no. 5, pp. 595-603.

Hong, S, and S. K. Park, (2012). "Uniaxial bond stress-slip relationship of reinforcing bars in concrete," $A d v$. Mater. Sci. Eng.

Hosseini, S.J.A, A. B. A. Rahman, M. H. Osman, A. Saim, and A. Adnan. (2015) "Bond behavior of spirally confined splice of deformed bars in grout," Constr. Build. Mater., vol. 80.

Lu, D. (2012) "Numerical Approach for the Mechanical Behavior of Fully Grouted Anchorage System Subjected to Pullout Test," Electron. J. Geotech. Eng., vol. 17.
Lu, Z., Z. Wang, J. Li, and B. Huang. (2017). "Studies on seismic performance of precast concrete columns with grouted splice sleeve," Appl. Sci., vol. 7, no. 6.

Paulay, T., and M. J. N. Priestley. (1992). Seismic Design of Reinforced Concrete and Masonry Buildings.

Raynor, D.J., D. E. Lehman, and J. F. Stanton, (2002). "Bond-slip response of reinforcing bars grouted in ducts," ACI Struct. J., vol. 99, no. 5, pp. 568576.

Rosyidah, A., G. M. R;, and E. Yasin. (2011). "Tinjauan Variasi Tebal Grouting Sikadur 31 CF Normal dan Panjang Penyaluran terhadap Daya Lekat Baja Tulangann pada Beton Mutu Normal," POLI Teknol., vol. 10, no. 1.

Wu, Y.-F and X.-M. Zhao. (2012). "Unified bond stress-slip model for reinforced concrete," J. Struct. Eng., vol. 139, no. 11, pp. 1951-1962.

Xing, G., C. Zhou, T. Wu, and B. Liu, (2015)."Experimental Study on Bond Behavior between Plain Reinforcing Bars and Concrete," vol. 2015.

Zhao, S.B., X. X. Ding, and S. M. Liu. (2012). "Numerical Simulation of Bond Properties of Steel Bars in Concrete with Machine-Made Sand," Appl. Mech. Mater., vol. 238, no. November 2012, pp. 176-180. 